\title{
Somatic Treatments for Mood Disorders
}

\author{
Moacyr A Rosa ${ }^{1}$ and Sarah H Lisanby ${ }^{*, 1}$ \\ ${ }^{1}$ Department of Psychiatry and Behavioral Sciences, Duke University School of Medicine, Durham, NC, USA
}

\begin{abstract}
Somatic treatments for mood disorders represent a class of interventions available either as a stand-alone option, or in combination with psychopharmacology and/or psychotherapy. Here, we review the currently available techniques, including those already in clinical use and those still under research. Techniques are grouped into the following categories: (1) seizure therapies, including electroconvulsive therapy and magnetic seizure therapy, (2) noninvasive techniques, including repetitive transcranial magnetic stimulation, transcranial direct current stimulation, and cranial electric stimulation, (3) surgical approaches, including vagus nerve stimulation, epidural electrical stimulation, and deep brain stimulation, and (4) technologies on the horizon. Additionally, we discuss novel approaches to the optimization of each treatment, and new techniques that are under active investigation.

Neuropsychopharmacology Reviews (2012) 37, 102-116; doi: I0.1038/npp.20II.225; published online 5 October 20II
\end{abstract}

Keywords: electroconvulsive therapy; vagus nerve therapy; repetitive transcranial magnetic stimulation; deep brain stimulation; transcranial direct current stimulation; depression; bipolar disorder

\section{INTRODUCTION}

Often in the history of medicine, we find treatments that emerge as promising but that disappear as time and experience prove them not efficacious or with side effects and risks that no longer justify their use. Before the advent of pharmacotherapy, in the 1930s and 1940s, there was a time of great enthusiasm surrounding the new somatic treatments that were being developed for psychiatric disorders (Shorter and Healy, 2007). Insulin coma and malarial fever therapy, for example, were intensely studied and clinically used. Convulsive therapies (chemical and electrical) also initially appeared in that era. After the advent of antidepressant medications and other pharmacologic treatments, only electroconvulsive therapy (ECT) remained as a nonsurgical and nonpharmacological tool originating in those early years still in routine clinical use over seven decades later. Today we are experiencing a re-emergence of nonpharmacological somatic treatments, possibly because of the limitations of medications for a significant percentage of the patients (Rush et al, 2006), and because engineering advances have enabled previously unprecedented tools for noninvasive neuromodulation.

${ }^{*}$ Correspondence: Dr SH Lisanby, Department of Psychiatry and Behavioral Sciences, Duke University Medical Center, Box 3950, Durham, NC 27710, USA, Tel: +1 919684 5616, Fax: +1 919681 5489,

E-mail: sarah.lisanby@duke.edu

Received 19 April 2011; revised 18 August 2011; accepted 18 August 2011
Controlled trials and clinical experience will show which of these will survive and develop in a way that can help our patients in their struggle with severe mood disorders. Here, we review recent developments across multiple categories of somatic treatments in depression: (1) seizure therapies, (2) noninvasive techniques, (3) surgical approaches, and (4) technologies on the horizon.

The seizure therapies involve the induction of a seizure, under anesthesia, either through the direct application of electricity to the scalp (ECT), or via the indirect induction of electricity in the brain through the application of rapidly alternating magnetic fields to the scalp (magnetic seizure therapy (MST)). In these cases, the therapeutic mechanism is hypothesized to be related to the nature of the seizure induced, however, the electric field itself, and its parameters, are thought to contribute to clinical outcomes.

The noninvasive techniques involve the transcranial application of electrical (direct or alternating) or magnetic fields to the scalp at subconvulsive levels. These interventions include repetitive transcranial magnetic stimulation (TMS), transcranial direct current stimulation (tDCS), and cranial electric stimulation (CES). Given the absence of an induced seizure, these interventions are hypothesized to act through plastic effects exerted by the repeated electrical stimulation of cortical circuits (in the case of alternating currents), or via potentiation of endogenous firing (in the case of direct currents).

The surgical approaches involve the implantation of devices to chronically stimulate brain structures directly 
TABLE 1 Comparison of Somatic Therapies for Mood Disorders

\begin{tabular}{|c|c|c|c|c|c|c|c|}
\hline Somatic therapy & Surgical? & Anesthesia? & Convulsive? & $\begin{array}{l}\text { Deep } \\
\text { brain? }\end{array}$ & Contactless? & Focal? & $\begin{array}{l}\text { Form of } \\
\text { stimulation }\end{array}$ \\
\hline CES — cranial electrical stimulation & N & $\mathrm{N}$ & $\mathrm{N}$ & N & $\mathrm{N}$ & $\mathrm{N}^{\mathrm{a}}$ & Electrical-AC \\
\hline ECS - epidural cortical stimulation & Y & Y & N & N & N & Y & Electrical-AC \\
\hline ECT_electroconvulsive therapy & $\mathrm{N}$ & Y & Y & Y & $\mathrm{N}$ & $\mathrm{N}$ & Electrical-AC \\
\hline MST_-magnetic seizure therapy & $\mathrm{N}$ & Y & Y & N & Y & Y & Magnetic \\
\hline NIR — near infrared light therapy & Y & Y & $\mathrm{N}$ & $\mathrm{N}$ & Y & Y & Optical \\
\hline Optogenetic & Y & Y & $\mathrm{N}$ & Y & Y & Y & Optical \\
\hline rTMS — repetitive transcranial magnetic stimulation & N & N & $\mathrm{N}$ & $\mathrm{N}^{\mathrm{a}}$ & Y & Y & Magnetic \\
\hline tDCS - transcranial direct current stimulation & N & $\mathrm{N}$ & $\mathrm{N}$ & $\mathrm{N}^{\mathrm{a}}$ & $\mathrm{N}$ & $\mathrm{N}^{\mathrm{a}}$ & Electrical-DC \\
\hline
\end{tabular}

${ }^{\mathrm{a}}$ Function of coil type or electrode array.

bLimited to vagal afferents.

(as in epidural electrical stimulation of lateral cortical regions, and deep brain stimulation (DBS) of deep targets) or indirectly (as in vagus nerve stimulation (VNS)). As with the transcranial application of alternating fields, surgical approaches are hypothesized to act through altering firing patterns (via inhibitory, facilitatory, or modulatory actions). Unlike the transcranial approaches, implanted approaches typically involve chronic, continuous stimulation while the transcranial approaches rely on the cumulative effects of intermittent application.

Table 1 summarizes the main aspects of the treatments/ techniques discussed in this article.

\section{SEIZURE THERAPIES}

\section{Electroconvulsive Therapy}

ECT remains the most efficacious and rapidly acting antidepressant treatment available today for acute severe major depression (Husain et al, 2004) and is recommended by the APA for depression, bipolar disorder, and other conditions (Weiner et al, 2001). Its drawbacks include cognitive side effects (Prudic et al, 2000) and the significant risk of relapse after remission (Kellner et al, 2006). While ECT is our oldest somatic treatment for mood disorders, the procedure has evolved substantially over the years, with progressive improvements in its safety. The currently used technique consists of delivering biphasic electrical stimulation through electrodes placed on the scalp. Bilateral (fronto-temporal) positioning is the more common electrode positioning used in the United States and probably around the world (Chanpattana et al, 2010; Gangadhar and Thirthalli, 2010; Rosa et al, 2006), although it is usually related with more cognitive side effects than other electrode placements (Sackeim et al, 2007b).
The longstanding controversy about the adoption of unilateral electrode positioning received new light with a series of studies by the Columbia University group (Sackeim et al, 1987; Sackeim, 1991) showing right unilateral ECT to be dose-dependent (one has to go well above the minimum charge needed to induce a seizure, the seizure threshold, to have clinical benefits). This electrode placement has a more benign profile of cognitive side effects and is considered part of standard practice by the APA guidelines (Weiner et al, 2001). The equivalent efficacy of RUL compared with BL and bifrontal approaches was confirmed in the recently published multi-center trial by the Consortium for Research on ECT (Kellner et al, 2010). Alternative approaches to further improve the focality of ECT, and thereby reduce its cognitive side effects, include novel electrode configurations, like in focal electrically administered seizure therapy (FEAST) (Spellman et al, 2009), in which a large electrode is placed over the parietal region and a small one on the forehead and unidirectional stimulus is delivered. Antidepressant effects of FEAST are yet to be reported. Work on novel electrode placements for ECT may be informed by realistic head modeling of the field distributions in the brain, such that dosing paradigms could be designed to target brain regions implicated in depression while avoiding those associated with adverse side effects (Lee et al, 2010).

Recent approaches to further improve the risk-benefit ratio of ECT include the use of ultrabrief pulse width, which substantially reduces the cognitive side effects without loss of efficacy (Sackeim et al, 2008), although response may take longer and mid-course dose adjustments may be necessary to ensure efficacy (Loo et al, 2010a). The advantage of ultrabrief pulse ECT is thought to stem from its relatively more efficient pulse width, being closer to the chronaxis for neural depolarization of mammalian neurons (Nowak and Bullier, 1998; Sekirnjak et al, 2006). 
New work on modeling of the electric field induced in the brain by various ECT configurations suggests that another parameter of the ECT stimulus that could be further optimized is the pulse amplitude (Deng et al, 2011). Conventional pulse amplitudes (0.8-0.9 A) are far in excess of the minimum needed for neuronal depolarization, and may expose the brain to unnecessarily highly field strengths (Peterchev et al, 2010b). Lowering pulse amplitude, and individualizing it, may be useful strategies for further optimization of an already highly effective treatment. The ability to induce seizures with substantially lower fields strengths has already been demonstrated (Rosa et al, 2010), and is not surprising given that seizure induction had already been shown to be feasible via magnetic stimulation, using induced electric fields far weaker than those seen with conventional ECT (see below for more on MST).

The recognition that individual parameters of the electrical stimulus pulse influences clinical outcomes in distinct ways calls for a re-examination of the methods we use to describe ECT dosage. The commonly used approach is to employ a summary metric, such as charge (expressed in millicoulombs), which collapses across all of the parameters. While convenient and in routine clinical use now, summary metrics like charge fail to reveal the individual contributions of specific parameters, such as pulse width and amplitude (Peterchev et al, 2010b). Innovative ways of more accurately defining the dosage of ECT, and of individualizing and determining in a safer way the seizure threshold (other than seizure titration), are being developed by our group.

\section{Magnetic Seizure Therapy}

The idea of inducing a therapeutic seizure using magnetic pulses was developed to try a more focal induction paradigm, avoiding medial temporal lobe regions, possibly related to adverse cognitive side effects (Lisanby et al, 2001). With repetitive TMS it is possible to target the cortical region to be stimulated in a way that is not possible with electrical stimulation, because of the lack of impedance of the scalp and skull to the passage of magnetic fields (Deng et al, 2011). The enhanced precision in targeting afforded by magnetic seizure induction offers the ability of focusing the electric field and also the site of seizure initiation in a more targeted fashion. In addition to its therapeutic potential, the ability to induce focal seizures from targeted brain regions opens the possibility of studying the mechanisms of action of seizure therapy in a way not previously possible (Rowny et al, 2009a). Specifically, in the case of conventional ECT both the volume of brain exposed to the electric field and involved in seizure expression are quite broad. In the case of MST, only superficial cortex is exposed to the induced fields, while the seizure may secondarily generalize to broader brain regions (Rowny et al, 2009b). Decoupling field exposure from seizure involvement opens the possibility to examine independently the contributions of these two aspects of seizure therapy (the seizure inducing field and the seizure itself).

As in ECT, MST requires muscle relaxation and general anesthesia, although the anesthetic dosage requirements for MST were lower in one study comparing it with ECT (White et al, 2006). The translational work was developed by our group using non-human primates as a model. This work with animals started in 1998 and showed it to be safe (Dwork et al, 2004, 2009) and with a more benign cognitive side effect profile (Lisanby et al, 2003b). The first human received MST treatment in 2000 (Lisanby et al, 2003a) and soon comparisons with ECT in within-subject (Lisanby et al, 2003a) and between-subject (White et al, 2006) trials followed. Trials from Germany (Kayser et al, 2009, 2010) and a case report from Australia (Hoy and Fitzgerald, 2010) have reported comparable efficacy of MST and ECT. A two-site controlled double-blind trial from our group is underway.

Currently, MST requires modified devices that limit its use in clinical practice, but novel parameter combinations and coils are being evaluated to optimize this technique and make it simpler and more accessible to the practitioner. These approaches are being explored to maintain efficacy while having a much better cognitive side effect profile than the gold standard ECT.

\section{NONINVASIVE TECHNIQUES}

\section{Repetitive TMS}

Repetitive TMS is now a very well-known brain stimulation technique that modulates cortical activity with several different uses ranging from neurophysiologic studies to the treatment of depression (George and Aston-Jones, 2010). Its basic principles are reviewed elsewhere (Wagner et al, 2007) but consist basically in a device that generates a pulsating electric current that passes through a coil creating an alternating magnetic field that depolarizes the underlying brain tissue. It is being tested for the treatment of a range of neurological and psychiatric disorders, but at present is only approved in the United States for the treatment of unipolar depression in adults that has failed to respond to a single medication trial (O'Reardon et al, 2007). Evidence supports that the likelihood of responding to TMS is better in those individuals who have failed to respond to a single medication trial in the current episode (Lisanby et al, 2009).

While other mood disorders have been investigated, unipolar depression is the most studied condition with TMS at present. According to the World Federation of Societies of Biological Psychiatry's guidelines (Schlaepfer et al, 2010) 'there is sufficient class I evidence of acute efficacy for TMS in depression in medication-free unipolar depressed patients. The large body of evidence from single site small sample trials suggests that it may also be useful clinically in moderately treatment-resistant patients, either alone or used adjunctively with medications. We thus recommend 
that psychiatrists consider using TMS in non-psychotic adults with major depression. Typically patients will have tried and failed at least one attempt at medication therapy, although this is not required. There are only limited data about using it in a maintenance fashion after acute response. As TMS efficacy data are continuing to emerge, the choice of stimulation parameters including frequency, laterality, intensity, and duration of treatment will need to be determined by a psychiatrist familiar with the relevant and recent TMS literature'.

A recent meta-analysis showed an overall weighted mean effect size for treatment of 0.39 (95\% confidence interval $0.25-0.54, z=6.52, p<0.0001$ ) (Schutter, 2009).

The effect size for the FDA-approved protocol with TMS as monotherapy for one failed trial is significant (0.9). For more resistant patients it is still modest and there remains great potential for identifying response predictors and modifying the treatment to enhance potency. Evidence for this can already be seen in recent studies that explore: (i) optimizing TMS pulse and train parameters, (ii) deeper coils, and (iii) combination therapy paradigms, coupling TMS with psychotherapy and/or pharmacotherapy.

Low-frequency stimulation and laterality. Low-frequency stimulation $(1 \mathrm{~Hz})$ of the right DLPFC has also been extensively studied (Stern et al, 2007). Lower frequencies tend to have a better safety profile for accidental seizure induction (Rossi et al, 2009). Its use for the treatment of mood disorders is based on the interhemispheric disequilibrium theory in depression (Herrington et al, 2010).

Results so far suggest an antidepressant effect as compared with medication (Bares et al, 2009), although, as with high frequency, it seems inferior to ECT (Hansen et al, 2011). There are data suggesting a similar efficacy of high frequency applied to the left side or low frequency applied to the right side (Fitzgerald et al, 2009a).

A study of patients that did not improve with low frequency to the right DLPFC TMS and subsequently received high frequency $(5$ or $10 \mathrm{~Hz}$ ) to the left DLPFC showed a significant improvement of both high frequencies (Fitzgerald et al, 2009b).

Another relatively unexplored approach it the bilateral stimulation that can be done sequentially (Conca et al, 2002; Fitzgerald et al, 2006) or simultaneously (Loo et al, 2003).

Optimizing TMS pulse and train parameters. Optimization of TMS parameters, for example, including theta burst paradigms (Chistyakov et al, 2010) and bilateral stimulation (Pallanti et al, 2010) are under intense investigation and hold some promise in enhancing the potency of the treatment. Some evidence suggests that increasing the number of pulses, and accelerating their application, may speed response (Hadley et al, 2011; Holtzheimer et al, 2010).

Another approach is to optimize the characteristics of the TMS pulse itself. Although ECT today uses brief rectangular pulses, conventional TMS stimulators employ dampened cosine waveforms. As seen in the case of ECT, the shape of the pulse affects physiological and clinical outcomes. This observation motivated the move from sine wave ECT to brief pulse ECT, and along with that transition came a dramatic lowering of side effects and increased efficiency in seizure induction. Conventional TMS devices, however, only allow very limited control over pulse shape. Recent engineering advances in controllable pulse TMS devices (cTMS), however, have now enabled the production of TMS pulses with user controlled characteristics such as pulse width, pulse shape, and directionality (Peterchev $e t a l$, 2010a). This device also offers the possibility of possibility of repetitive high-frequency unidirectional stimuli, which studies suggest may be more efficient in inducing plasticity (Sommer et al, 2006).

Deeper coils. New coils are being developed, like the H-coils (Harel et al, 2011) and other designs (Deng et al, 2011), which have a deeper penetration of the magnetic fields. Given the focality/depth trade off, these coils also stimulated a larger volume of brain. Although it is possible (Levkovitz et al, 2009), there are no data yet to suggest that by virtue of the increased volume or increased depth these coils will have more potent effects risk of accidental seizures also seems to be increased.

Combination therapy-pharmacological enhancement. While most of the trials on TMS in the treatment of depression and other conditions used TMS as an add-on to stable pharmacotherapeutic treatments, the potential interaction and synergy between TMS and pharmacotherapy has rarely been the topic of direct study. Clinical trials typically describe the ancillary medication treatments, and ensure that the dosage have been stable before the TMS application, so that observed clinical effects could be safety attributable to the TMS and not delayed onset of action of the concomitant medication. Although this is reasonable, it fails to address the possibility that the action of TMS could be altered in the presence of receptor agonism or antagonism. Should such interactions exist, they may not only be a source of noise to avoid and control for, but may be a target and potential avenue for optimization.

Effects of pharmacological agents on responses to TMS have been documented using a variety of measures including electromyography (for a review, see Paulus et al, 2008) and TMS/fMRI interleaving (Li et al, 2010). This should not be surprising because TMS induces release of endogenous neurotransmitters, which in turn act at pre and post-synaptic receptors, and should receptor function be subjected to agonism or antagonism at the time of TMS, altered effects of the TMS would be expected. Furthermore, neuronal depolarization induced by TMS is itself an event mediated by ion channel function, thus ion channel agents would be expected to affect this action.

Although the action of a single TMS pulse can be altered by pharmacology, the action of a train of pulses may likewise be impacted. On the basis of the hypothesis that lasting effects of trains of TMS may come about through mechanisms of plasticity, then pharmacological agents affecting plasticity may be useful targets to enhance the action of TMS. Effects of D-cycloserine on plasticity induced 
by theta burst stimulation have already been reported (Teo et al, 2007).

Combination therapy - cognitive/behavioral enhancement. As with the relative inattention to concomitant medication, concomitant psychotherapy has rarely been the focus of study in TMS trials and there is no certainty on how many patients in these trials were actually in ongoing psychotherapy. Is this merely a time-saver, or could simultaneous TMS and psychotherapy have a synergistic effect? Evidence in the neurorehabilitation literature already suggests that TMS can prime response to motor training and possibly aide in motor recovery post stroke when coupling cortical TMS with motor training. It has been proposed that the same could be true of cognitive rehabilitation (Miniussi and Rossini, 2011). Rather than physical therapy, the conjoint administration of a cognitive/behavioral therapy during targeted induction of plasticity via TMS could theoretically enhance action, as has been recently reported in a proof of concept study in post-traumatic stress disorder (Osuch et al, 2009). The extension of this concept to depression and cognitive/behavioral approaches to mood disorders is at the early stages of exploration (Vedeniapin et al, 2010).

\section{Transcranial Direct Current Stimulation}

tDCS (also called 'polarization') has some important advantages over its counterparts: it is inexpensive, it is relatively safe (although case reports of skin lesions or burns were reported-(Palm et al, 2008)), it is easy to use, and has few side effects (slight tingling under the electrodes, headache, fatigue, and nausea are the most common). It consists of using two sponge electrodes soaked with saline solution that are placed on the head (Figure 1). It uses extremely low currents $(1-2 \mathrm{~mA})$ that are in the range of

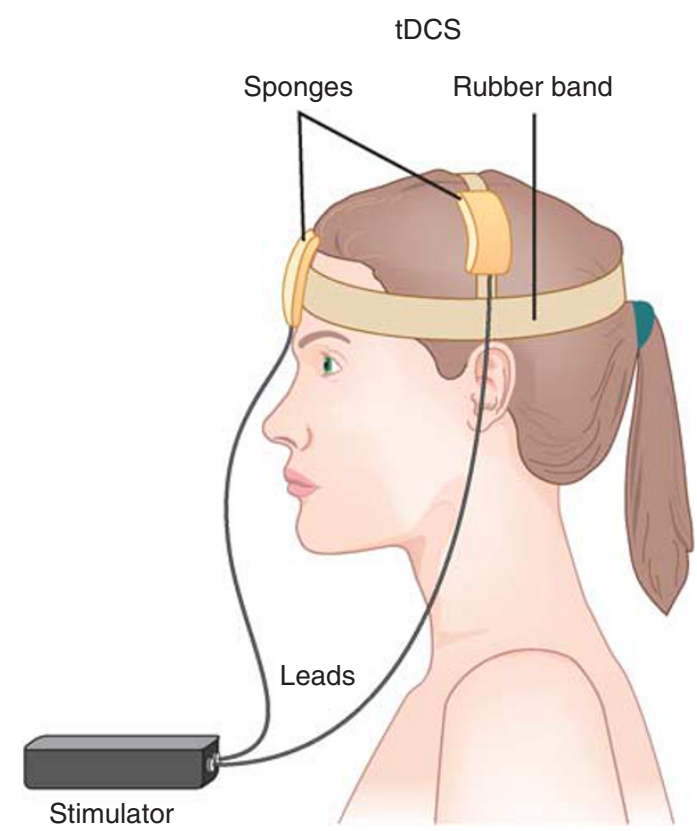

Figure 1. Transcranial direct current stimulation (tDCS). those used in portable flashlights. The procedure entails a unidirectional constant (as opposed to pulses of stimulation used in all other forms of brain stimulation) flux of lowintensity current from one electrode to the other (the first one is the anode and the second is the cathode). Early animal work showed that cortex activity could be changed according to the region being stimulated and if it was under the cathode (where there would be reduced activity because of hyperpolarization) or the anode (where there would be increased activity because of sub threshold membrane depolarization) (Scholfield, 1990).

It was demonstrated in humans that the after-effects of tDCS depend on modifications of NMDA receptor-efficacy. The after-effects of tDCS are blocked by the NMDA receptor antagonist dextrometorphan, and prolonged by the partial NMDA receptor-agonist D-cycloserine (Liebetanz et al, 2002; Nitsche et al, 2003, 2004). This tDCS polaritydependent alteration of NMDA receptor function seems to be initiated by the respective membrane potential shift and probably by the accompanying cortical activity modification, because it is prevented by the sodium channel blocker carbamazepine. Intraneuronal calcium concentration also contributes, because calcium channel antagonists eliminate the excitability-enhancing after-effects of anodal tDCS (Nitsche et al, 2003).

There were early reports of neuromodulation by tDCS (Bindman et al, 1964; Creutzfeldt et al, 1962; Purpura and McMurtry, 1965) that suggested a possible role as a therapeutic tool. There were some open pilot studies and clinical observations showing some effects (eg, Baker, 1970; Nias and Shapiro, 1974; Ramsay and Schlagenhauf, 1966) but those were not confirmed in a controlled trial (Arfai et al, 1970) and no further studies were pursued at that time.

Recently, tDCS was rediscovered as a possible tool for the treatment of depression, possibly based on the success obtained by TMS in modulating prefrontal cortex excitability and showing clinical efficacy.

The first randomized, double-blinded, sham-controlled study, the effect of tDCS on depression was published as a letter and evaluated a small sample of 10 patients with first episode major depression without antidepressant medication treatment (Fregni et al, 2006). After five sessions with $1 \mathrm{~mA}$ for $20 \mathrm{~min} /$ day, an impressive result was seen with four out of five patients benefiting from active treatment and none in the sham group and the mean reduction in the depression scores were between 60 and $70 \%$, relative to baseline values.

The same group tried the technique with a higher intensity $(2 \mathrm{~mA})$ in a larger sample $(n=40)$ randomized to three different groups: anodal stimulation of the left dorsolateral prefrontal cortex $(n=21)$, anodal stimulation of the occipital cortex $(n=9)$, or sham stimulation $(n=10)$. The number of responders was significantly larger in the prefrontal stimulation group ( $8 v s \quad 2 v s \quad 0$, respectively). Benefits were reported to have lasted at least 1 month after the end of the trial (Boggio et al, 2008). However, an 
independent group (Loo et al, 2010b) did not replicate these findings studying 40 depressed patients for 5 days with $1 \mathrm{~mA}$ current strength. tDCS was also tried in bipolar depressed patients in an open study with good effects (Brunoni et al, 2011).

tDCS clearly has effects on cortical excitability but with relation to treating mood disorders, although promising, published data are still not consistent or conclusive and there is a need of more sustainable data from wellcontrolled studies. There are also opportunities to refine the technique to improve its focality through novel electrode designs (Bikson et al, 2008; Minhas et al, 2010).

\section{Cranial Electrical Stimulation}

CES also called transcranial electrostimulation (Boutros and Krupitsky, 1998) is perhaps the oldest way of stimulating the brain noninvasively (Figure 2). It includes a variety of different techniques that have in common the use of lowlevel alternating electrical (low current amplitude) signals applied to the scalp or earlobes (Klawansky et al, 1995). Although tDCS can be considered a form of CES, it was treated separately because there are data suggesting that its effects are quite different in the brain physiological effects (Stagg and Nitsche, 2011). There is also a 'mixed' form of CES in which constant electric current (similar to tDCS) is combined with pulses of alternating current. This form of stimulation was used in Russia especially for narcoanalgesia (Boutros and Krupitsky, 1998).

It has been in wide clinical use in Europe since 1950 and in the United States since the 1960s, and became FDA sanctioned for the treatment of depression, anxiety, and insomnia in 1978. CES was never subjected to the level of regulatory review now required for new technologies because it was 'grandfather-ed' based on a device that predated the current FDA regulations. The device is being

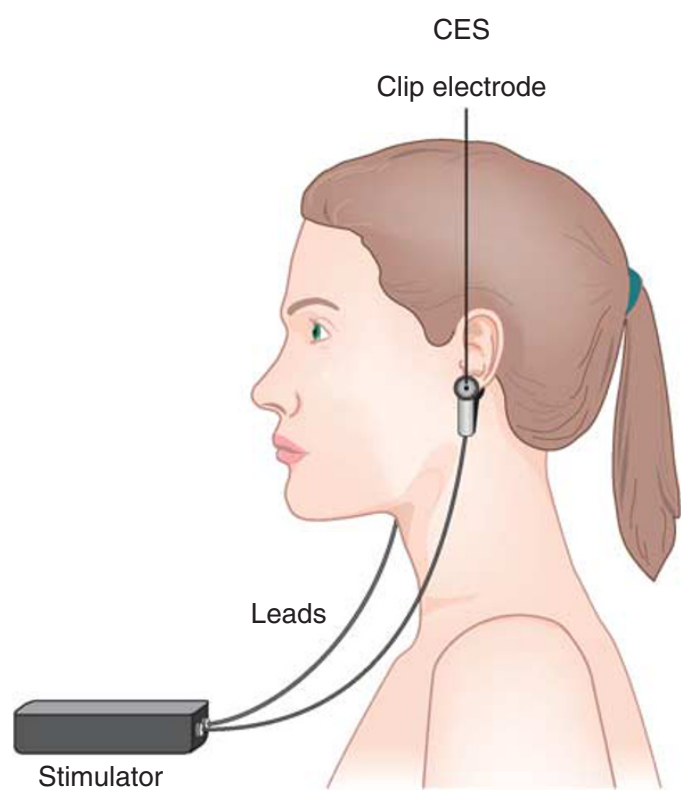

Figure 2. Cranial electric stimulation (CES). marketed and sold for these conditions; however, there is a relative lack of controlled clinical trials supporting its efficacy. Despite the wide use of, no well-controlled trials of its efficacy have been done, in part because of improper blinding of the operator. It has also been proposed for the treatment of pain, headaches, fibromyalgia, smoke cessation, and opiate withdrawal (Boutros and Krupitsky, 1998; Bystritsky et al, 2008).

The output parameters of the commercially available CES devices vary widely. The Fisher-Wallace Cranial Stimulator (model SBL500-B), which became FDA sanctioned for the treatment of anxiety, insomnia, and depression in 1990 (510 K approval), uses $0.5-2 \mathrm{~mA}$ alternating currents administered as rectangular pulses modulated in three frequencies $(15,500$, and $15000 \mathrm{~Hz})$ with alternating polarity at $7.5 \mathrm{~Hz}$. This is the same device as the Liss Cranial Stimulator (model SBL201-M), a class III device, which has been marketed since the 1970s for treatment of depression, anxiety and insomnia. The Alpha-Stim Stress Control System generates bipolar, asymmetric, rectangular pulses with a frequency of $0.5,1.5$, or $100 \mathrm{~Hz}$ and a current amplitude that can be adjusted continuously to provide between 10 and $600 \mu \mathrm{A}$. In addition to these, there are several other available manufacturers with a range of electrode placements (eg, cathodes over the orbits and anodes over the mastoids; cathodes over frontal areas and anodes over occipital regions, and so on). The waveform parameters of the devices are wide ranging with currents from 0.1 to $4 \mathrm{~mA}$, frequencies from 0.5 to $167000 \mathrm{~Hz}$, pulse width from 0.00003 to $1 \mathrm{~s}$, and duration of application from 5 min to 3 consecutive months. The lack of standardization in practice makes drawing conclusions regarding its clinical potential in mood disorders fraught.

Headache and nausea are the most common side effects described, followed by skin irritation (Kirsch and Smith, 2000).

The mechanism of action of CES is unclear. There is evidence that weak cranial currents $(0.26 \mathrm{~mA}, 0.75 \mathrm{~Hz})$ applied during sleep can affect memory and brain oscillations (Kirov et al, 2009; Marshall et al, 2006). Furthermore, weak electric fields $(\sim 0.5 \mathrm{~V} / \mathrm{m}=\sim 2 \mathrm{~mA})$ can affect neural function (Deans et al, 2007; Radman et al, 2007). Alterations in neurotransmitters and hormones have been described (Ferdjallah et al, 1996), including increased thyroxine production (Jarzembski, 1985). Also, increase in platelet MAO-B activity and plasma GABA concentrations were reported (Klawansky et al, 1995). Finally, changes in EEG readings during and after stimulation have been described, especially slowing of alpha waves (Jarzembski, 1985). However, there is a lack of significant work in animal models, and there remains the possibility that the effects may be at least in part mediated via cranial nerve stimulation rather than direct brain stimulation.

CES has been used in a variety of disorders, but especially anxiety, headaches, and insomnia (Klawansky et al, 1995). There is no controlled trial on its use for major depression or other affective disorders, although some benefit was 
reported in patients with comorbid alcoholism and depression (Krupitsky et al, 1991), and it has been reported to have anxiolytic effects in an open-label trial of 12 patients (Bystritsky et al, 2008). Little consistency exists in the literature surrounding the specific parameters and electrode placements used, and there are no controlled trials on its use, making it difficult to draw conclusions about its potential value. In their meta-analysis, Klawansky et al (1995) concluded insufficient controlled evidence existed and that available evidence was probably not adequately blinded.

\section{SURGICAL APPROACHES}

\section{Vagus Nerve Stimulation}

The use of VNS for chronic or recurrent depression (uni or bipolar) was approved in 2005 by the FDA, for patients that have failed to respond to at least four antidepressant trials (Figure 3).

Stimulating the vagus nerve to treat mood disorders was supported by several lines of evidence. Beneficial effects on mood were seen in epileptic patients that used VNS (Elger et al, 2000; Harden et al, 2000). Also, VNS is successfully used for epilepsy and there is evidence of beneficial effects of anticonvulsants as mood stabilizers and antidepressants (Goodwin and Jamison, 2007). In addition, ECT is also hypothesized to act, in part, through its anticonvulsant properties (Sackeim, 1999). Effects on different neurotransmitters (Ben-Menachem et al, 1995) and imaging findings (Henry et al, 1998) also favor this indication of VNS.

The mechanism of action is not fully understood, but stimulation is intended to enter the brain through the primary afferent pathways of the nerve that connect to the nucleus tractus solitarius and from it to many brain areas, including the forebrain, largely through the parabrachial nucleus and the locus ceruleus (Crawley, 1985; Frisina et al, 2009; Momose-Sato and Sato, 2011). VNS does, for instance,

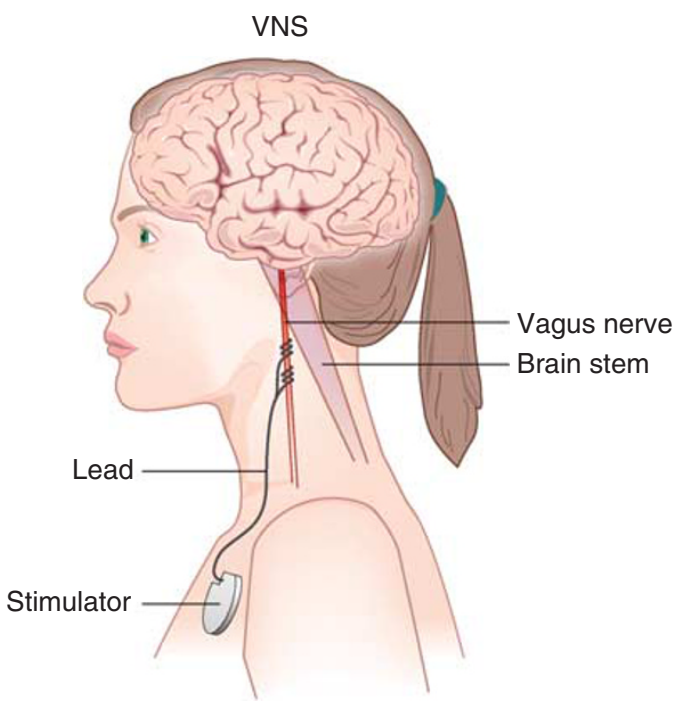

Figure 3. Vagus nerve stimulation (VNS). enhance cortical inhibition and affect hippocampal plasticity (Zuo et al, 2007). Interestingly, ECT has also been demonstrated to increase cortical inhibition (Bajbouj et al, 2006).

Side effects include hoarseness, cough, and neck or jaw pain.

The first VNS implant for depression was performed in July 1998 at the Medical University of South Carolina in Charleston (Rush et al, 2000), a decade after the first human epilepsy implant (Penry and Dean, 1990). The left vagus is used based on the knowledge that right vagus is closely associated with the cardiac atria and the left vagus with cardiac ventricular function. This is supported by the lack of cardiac effects of left VNS although stimulation parameters could also be a possible explanation. The first pilot study included 30 patients with resistant major depression (uni and bipolar) and VNS showed response in $40 \%$ after 10 weeks, an encouraging result given the degree of resistance of the sample.

The only published double-blind, randomized, controlled study (Rush et al, 2005a) studied 235 outpatients with depression (unipolar, $n=210$ and bipolar, $n=25$ ) and the effects of acute (10 weeks) treatment with VNS. The groups did not significantly differ in response rates (active $=15.2 \%$ and sham $=10.0 \%$ ). This well-controlled study found no supporting evidence for acute antidepressant benefits of VNS. A parallel but not randomized group receiving 'treatment as usual' was followed for 12 months and compared in an open-label fashion with the VNS group (George et al, 2005). After 1 year, response rate for the VNS group was 27 and $13 \%$ for the treatment as usual group (statistically significant). The latter study was the basis for FDA approval of VNS for resistant depression (Rush et al, 2005b).

There are some published studies dealing with long-term follow-up on the benefits of VNS. Schlaepfer et al (2008b), in an open study, report that after a remission and response rate of 37 and $17 \%$ in the first 3 months, a sustained response (no relapse in 1 year) of $44 \%$ was observed. Nahas et al (2005) report a response rate of $42 \%(25 / 59)$ after 2 years. Also, Sackeim et al (2007a) analyzed the durability of response to VNS. In a pilot and a pivotal study, they classified the outcomes as early responders (50\% reduction in symptom scores within 3 months), later responders (same reduction within 12 months) and non-responders. In the pilot study, $72.2 \%$ and $61.1 \%$ of early responders $(n=18)$ were responders at 12 and 24 months, respectively; $78.8 \%$ of late responders $(n=14)$ were responders at 24 months. In the pivotal trial, of early responders $(n=30)$, $63.3 \%$ and $76.7 \%$ maintained response at 12 and 24 months, respectively; of late responders $(n=40), 65.0 \%$ maintained response at 24 months.

A recent naturalistic study (Bajbouj et al, 2010) assessed the efficacy and the safety of VNS in 74 European patients with therapy-resistant major depressive disorder. After 2 years, response rate was $53.1 \%(26 / 49)$ and remission was $38.9 \%$ (19/49). Important to note is that two patients 
committed suicide during the study; no other deaths were reported. The results of this 2-year open-label trial suggest a clinical response and a comparatively benign adverse effect profile among patients with treatment-resistant depression.

All these results should be contrasted with naturalistic outcomes reported in the literature for patients with treatment-resistant depression receiving treatment as usual which. In a naturalistic outcome, Dunner et al (2006) found a response rate of $11 \%(13 / 112)$ in 12 months and $18 \%$ $(19 / 103)$ in 24 months. Only 5 out of the 13 responders at 12 months were still responders at 24 months. A similar thing was observed with remission, being $3.6 \%(4 / 112)$ at 12 months and $7.8 \%(8 / 103)$ at 24 months. Similarly, only one of the four remitters remained a remitter at 24 months.

For bipolar disorder, a pilot prospective, open-label, study of nine rapid-cycling bipolar patients (excluded from larger trials) found evidence of benefit over 12 months (Marangell et al, 2008).

\section{Deep Brain Stimulation}

Direct electrical stimulation of the brain was tried in the 1960s (Heath, 1963), but modern DBS started in the 1980s with works on movement disorders (Leiphart and Valone, 2010) (Figure 4).

DBS, although more invasive than the other techniques, is arguably the most focal way of treating mood disorders available (Butson and McIntyre, 2006). An area in the millimeter range is usually used for stimulation. Different brain regions have been tried, some based on beneficial effects on depression while treating other primary disorder (eg, Parkinson or obsessive-compulsive disorder), and some based on hypothetical pathways related to mood symptoms. Animal work on DBS is largely focused on exploring the mechanisms of action (Hamani et al, 2010). A number of regions have been proposed with DBS to treat depression, with some degree of overlap in the circuits that they modulate (for a review, see Hauptman et al, 2008).

\section{DBS}

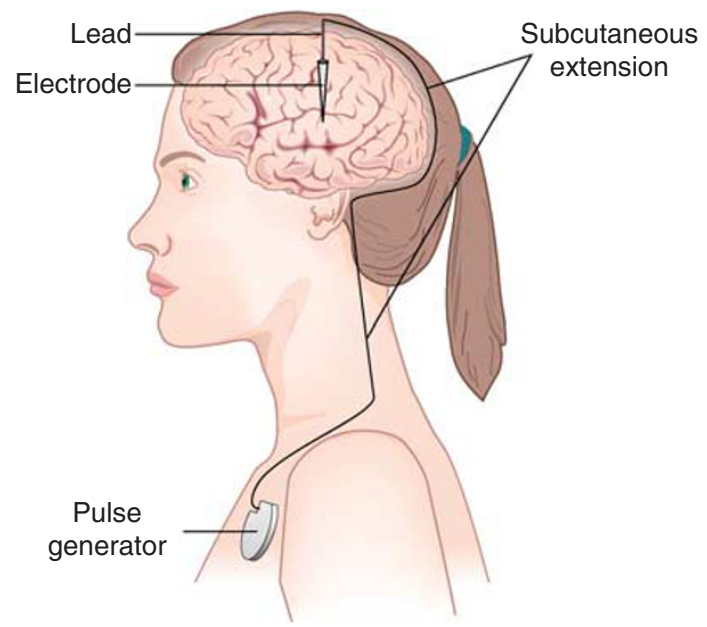

Figure 4. Deep brain stimulation (DBS).
Most of the studies used stimulation of the subgenual cingulate, the ventral anterior internal capsule (ventral capsule/ventral striatum (VC/VS)) and the nucleus accumbens. There are also case reports of stimulation of the inferior thalamic peduncle and lateral habenula (Figure 5). These will be briefly discussed.

The subgenual cingulate cortex. The subgenual cingulate cortex (more specifically, the white matter of Brodmann's area 25). Is a region connected to the nucleus accumbens and limbic cortical loop. It is also connected to orbitofrontal, dorsomedial prefrontal, dorsolateral prefrontal, and dorsal cingulate cortices. Increases in blood flow are seen in this area during induced sadness (Vago et al, 2011). Early studies have implicated the subgenual cingulate cortex (Cg25) in acute sadness and antidepressant effects (Mayberg et al, 1999; Seminowicz et al, 2004) and a decrease in Cg25 activity has been associated with immediate clinical response to a number of antidepressant treatments including serotonin reuptake inhibitors (Mayberg et al, 2000), ECT (Nobler et al, 2001), TMS (Mottaghy et al, 2002), and ablative surgery (Dougherty et al, 2003). DBS has been thought as an instrument to functionally inhibit the activity in this region. Mayberg et al (2005), implanted DBS electrodes in the bilateral subgenual cingulate cortex in six patients with treatment-resistant depression. Chronic stimulation at $130 \mathrm{~Hz}$ resulted in a significant response and remission of depression in four of the six patients at 6 months; in the two remaining patients, one experienced a significant reduction in depression over the first 4 months that fluctuated over time and remained submaximal, and the other patient had no response. A subsequent extension report came from this group with 20 implanted patients. In all, $12 / 20$ patients had a reduction of at least $50 \%$ in the 17-item Hamilton Rating Scale for Depression (HRSD-17) score and 7 patients met criteria for remission (HRSD$17 \leqslant 7)$. PET studies of some responders showed widespread changes in cortical and limbic metabolic activity, including increased activity in lateral prefrontal cortex and Cg25WM, but a reduction in Cg25 grey matter (Lozano et al, 2008).

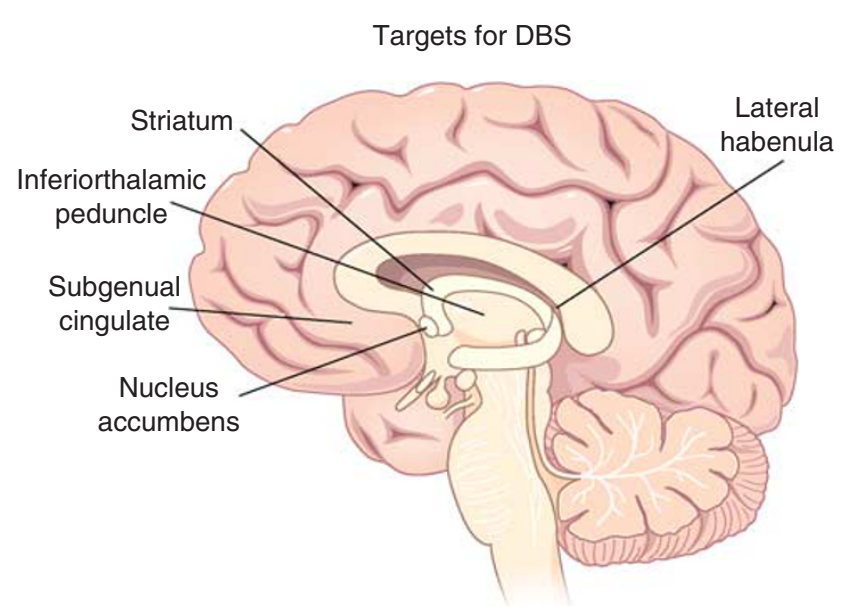

Figure 5. Targets for deep brain stimulation (DBS). 
This group recently published an extended follow-up of these patients. After an initial 12-month study of DBS, patients were seen annually and at a last follow-up visit. The average response rates 1,2 , and 3 years after DBS implantation were $62.5 \%, 46.2 \%$, and $75 \%$, respectively. At the last follow-up visit (range $=3-6$ years), the average response rate was $64.3 \%$, two patients died by suicide during depressive relapses (Kennedy et al, 2011).

Ventral anterior internal capsule. A region that has been a DBS target for treating depression is the same used for the treatment of OCD patients (Nuttin et al, 1999) that got better from depressive symptoms, the ventral anterior internal capsule (VC/VS). In this case, the nucleus accumbens is not the target. Malone et al (2009) attempted bilateral VC/VS DBS in 15 patients with treatment-resistant depression. They found that the proportion of patients with at least $50 \%$ reduction in HRSD-24 was $47 \%$ at 3 months, $40 \%$ at 6 months, and $53 \%$ at last follow-up, while remission rates with HRSD-24 were $20 \%$ at 6 months and $40 \%$ at last follow-up.

Nucleus accumbens. The nucleus accumbens/VS are regions that have long been regarded as part of the circuitry associated with depression and drug addiction (Monk et al, 2008; Thomas et al, 2000). The first case report of DBS implant in this region was for a patient with OCD and major depression. Stimulation of the bilateral NAC and ventral caudate at $130 \mathrm{~Hz}$ resulted in significant relief from depression and anxiety, with a remission at 6 months (Aouizerate et al, 2004). Subsequently, three patients had bilateral implantation (Schlaepfer et al, 2008a) with improvement in anhedonia and depression. In addition to other effects, there was an increases in the metabolism of dorsolateral and dorsomedial prefrontal cortices. Metabolism of the ventral and ventrolateral medial prefrontal cortex, shown in previous studies to be hyperactive in depression, was decreased. In an extension of this study (Bewernick et al, 2010), 10 patients with refractory depression received bilateral stimulation to the nucleus accumbens, 5 (50\%) of which had a response associated also with a reduction in anxiety after 12 months.

Inferior thalamic peduncle. The inferior thalamic peduncle, is a bundle of fibers connecting the thalamus to the orbitofrontal cortex and aids the inhibition of input of irrelevant stimuli, providing selective attention. Velasco et al (2005) identified this region as a potential target to treat depression. This region, along with the orbitofrontal cortex is hyperactive in depression and reverts with pharmacological treatment. The first case treated with DBS implanted in this site was a 49-year-old woman with severe TRD and multiple hospitalizations (Jimenez et al, 2005) that improved with the treatment. Patient maintained remission scores during 8 months of active stimulation without antidepressant medication. When stimulation was turned off, fluctuations on depression scores were observed and disappeared when the device was again turned on by month 20. Borderline personality disorder and bulimia were also present and may complicate generalization of conclusions.
Lateral habenula. Finally, the last region tested so far as a DBS target for depression is the lateral habenula (Sartorius and Henn, 2007), a region implicated in reward processing and emotional decision making. This region is located in the diencephalon, behind the thalamus and consists of a group of nerve cells neighboring the pineal gland. It is traditionally divided in a lateral part (limbic) and a medial part (motor). The putative use of this region is based on animal work showing that when the lateral habenula is inhibited by electrical stimulation in rats, norepinephrine in the hippocampus/prefrontal cortex increases, as does serotonin in the striatal circuits. Reduced depressive behaviors were observed in an animal model following lesions of the lateral habenula, and this effect was thought to be mediated through increased dorsal raphe serotonin (Yang et al, 2008). On the other hand, DBS of the lateral habenula has been reported to attenuate positive rewardassociated reinforcement. The first case report reached remission after about 20 weeks of stimulation and had a relapse a couple of days after the DBS unit was switched to off because of an incidental bicycle accident. The patient achieved remission again after 12 weeks of high voltage $(10.5 \mathrm{~V})$ stimulation (Sartorius et al, 2010). Intracranial hemorrhage is the most common surgical complication (Binder et al, 2003). It has been reported to be around 1-2\% in large series of patients with implants for the treatment of Parkinson. Hemorrhage can be small and asymptomatic or can result in severe neurological deficit. No severe hemorrhagic complications were published so far for patients treated DBS for depression (Blomstedt et al, 2011). Side effects such as depression and suicide ideation have been reported, but usually associated with misplacement of electrodes (Berney et al, 2002; Bezerra et al, 1999).

Side effects/complications in depressive implanted patients included: dysphagia, swollen eye, pain, erythema, anxiety increase, sweating, disequilibrium, hypomania, paresthesia, agitation, headache, lead dislodgement, psychotic symptoms, muscle cramps, affection of vision (with nucleus accumbens stimulation); seizure (one case in 20 implanted), infections, perioperative pain, worsening of mood (with subgenual cingulate cortex stimulation); on hypomanic episode (out of 15 implanted with VC/VS stimulation). No complications were reported in the cases with DBS in the inferior thalamic peduncle or lateral habenula (Blomstedt et al, 2011).

The most appropriate target, optimal stimulation parameters, and long-term effects and efficacy remain uncertain. What is clear is that large-scale trials must be conducted to adequately assess the safety and efficacy of stimulation for depression. Data from such studies will provide information regarding optimal target localization, stimulation parameters, and adverse effects. Also important will be the illumination of the mechanism of action. Although DBS is often thought of as a 'virtual lesion', recent evidence demonstrates that the effects of DBS can be subtler and may modulate information flow rather than halt it. For example, studies in Parkinson's disease indicate that DBS of the 
subthalamic nucleus appears to exert its therapeutic action by suppressing pathological oscillations in a specific frequency range (Eusebio et al, 2011). According to McIntyre et al (2004), the general hypothesis to explain the mechanism of high-frequency DBS stimulation are depolarization blockade, synaptic inhibition, synaptic depression, and stimulation-induced modulation of pathological network activity. Using the results from functional imaging, neurochemistry, neural recording, and neural modeling experiments, these investigators suggest that stimulation-induced modulation of pathological network activity represents the most likely mechanism of DBS. In addition, computational modeling of frequency-specific action of DBS suggests it may act by regularizing pathological patterns of activity within thalamic/basal ganglia circuits (Dorval et al, 2009). While oscillatory abnormalities in depression are incompletely understood, such modeling work may ultimately inform the appropriate targets and dosing paradigms for application in mood disorders.

\section{Epidural Cortical Stimulation}

Although DBS has the drawback of requiring invasive electrode implantation, chronic electrical stimulation of superficial targets can be achieved less invasively via implanted epidural stimulators, a technology that has been used in pain treatment, stroke recovery, and movement disorders. A multi-center industry sponsored trial attempted left sided prefrontal cortical stimulation and reported modest success (Dougherty et al, 2008). One group did an open-label case series of five patients implanted with bilateral epidural prefrontal cortical stimulation (targeting the anterior frontal poles and midlateral prefrontal cortex) and found on average 55\% improvement in depression scores (Nahas et al, 2010). While work with this technology is at an early stage, its lower invasiveness relative to DBS merits further study.

\section{Ablative Techniques}

Surgical ablative approaches were tried in the past to treat neurological and psychiatric disorders and have undergone a renaissance in recent years. Ablations guided some of the DBS electrode positioning for movement disorders (Benabid et al, 1991) and provided the rationale for some DBS approaches for psychiatric disorders (Leiphart and Valone, 2010).

The advances that were made in neurosurgical techniques, in particular the development of stereotactic operation, have dramatically improved the accuracy, making it possible to place tiny lesions with high precision. These lesions have minimal side effects in individual brain regions, their substructures or fiber tracts of the projection pathways (Juckel et al, 2009). Techniques relevant to the treatment of depression are cingulotomy and limbic leucotomy.
Cingulotomy uses thermocoagulation to perform a bilateral lesion (about $1 \mathrm{~cm}$ wide and extend dorsally $2 \mathrm{~cm}$ into the callosum) of the cingulum. The aim is to interrupt the thalamo-fronto-cortical pathways and thus relieve anxiety (Cosgrove and Rauch, 2003). Limbic leucotomy combines the cingulotomy with subcaudate tractotomy (lesion of the white substance) anterior to the head of the caudate nucleus. It destroys fiber strands between the prefrontal cortex and the limbic system (connections between the prefrontal cortex and the hippocampus, amygdala, thalamus, and hypothalamus) and leads to a secondary degeneration of the dorsomedial thalamic nucleus.

Therapeutic effects usually take long (about 1 year) to manifest after the surgery. The most common side effect is spontaneous seizures (1-2\% of patients). It should be kept in mind that these techniques have the characteristic of being irreversible and more studies are needed define its place in the clinical setting.

\section{TECHNOLOGIES ON THE HORIZON}

An ever-broadening array of approaches are beginning to be explored, as novel technologies become available and older technologies are rediscovered or repurposed. Examples on the horizon include focused ultrasound (FUS), near infrared light therapy (NIR), low field magnetic stimulation (LFMS), and optogenetic stimulation.

\section{Focused Ultrasound}

In addition to being an imaging modality, ultrasound can be used, contingent upon the parameters and apparatus employed, in a focused fashion to achieve several types of effects of potential relevance to mood disorders such as nonsurgical ablative approach, or to focally impact blood/ brain barrier for targeted drug delivery. For the purpose of this review, it could be thought of as a putative means of neurostimulation.

The potential for low-intensity, low-frequency ultrasound to stimulate neuronal circuits has been reported to induce neuronal activation in ex vivo preparations, presumably via activating voltage-gated sodium and calcium channels (Tyler et al, 2008). The ability to achieve similar effects noninvasively through the intact skull remains to be demonstrated.

\section{Near Infrared Light Therapy}

NIR is an emerging neurostimulation technology that is able to depolarize neurons in vitro (Katz et al, 2010), but its cellular mechanism of action remains unresolved. Recent work has shown that a pulsed laser light placed at a distance is able to modulate the growth of axons of primary neuronal cell cultures (Mathew et al, 2010). Its place as a neuromodulation tool is still uncertain. 


\section{Low Field Magnetic Stimulation}

The serendipitous observation that bipolar patients receiving echo planar magnetic resonance spectroscopic imaging (EP-MRSI) reported mood improvement (Rohan et al, 2004) led to the hypothesis that the oscillating magnetic fields (LFMS) applied during the EP-MRSI imaging sequence may represent a novel form of neurostimulation possessing mood altering properties. In contrast to the high-intensity magnetic fields used with TMS, LFMS employs relatively weak magnetic fields $(<10 \mathrm{G})$ and electric fields $(\sim 1 \mathrm{~V} / \mathrm{m})$ applied uniformly at $1 \mathrm{kHz}$ and a pulse width of $0.25 \mathrm{~ms}$, resulting in a bidirectional pulse training of alternating polarity.

Supplementing the initial anecdotal observation initially reported in 23/30 bipolar patients receiving real EP-MRSI compared with $3 / 10$ receiving sham, a controlled study in rats demonstrated activity of LFMS in a rodent model of learned helplessness (Carlezon et al, 2005). That these fields could plausibly change brain function was supported by a recent FDG-PET study finding the degree of metabolic decrease was correlated with applied field strength, although no changes in mood ratings were observed in the 15 healthy volunteers tested (Volkow et al, 2010). The potential value of this approach in the treatment of depression is yet to be examined systematically.

\section{Optogenetic Stimulation}

Microbial proteins called opsins are light sensitive molecules that can be introduced into neurons and function as ion channels that open or close according to light exposure. One of these is called channelrhodopsin-2 (ShR2) and allows $\mathrm{Na}+$ ions to enter the cell following exposure to $\sim 470 \mathrm{~nm}$ blue light (Zhang et al, 2007). The advent of this technique has raised the possibility of enhancing the selectivity of neurostimulation via implanted DBS by targeting specific fiber tracts that overlap in space. The ability to selectively activate or inactivate specific projection neurons to the same target has great intrinsic appeal as a more sophisticated tool than conventional DBS. This technology also has the advantage of being a contactless form of stimulation relying on photo-activation. Although this technology still requires surgical implantation of the light emitting electrode, its potential uses in studying and 1 day potentially treating mood disorders are worth tracking. Indeed, antidepressant effects of optogenetic stimulation of medial prefrontal cortex have already been reported in a chronic social defeat stress model in rodents (Covington et al, 2010).

\section{FUTURE RESEARCH DIRECTIONS}

The family of somatic therapies available for mood disorders is broad, varied, and rapidly growing. Engineering advances are expanding the available toolbox, and neuroscience advances are informing the selection of targets and stimulation paradigms.
ECT remains a major treatment for severe depression, especially when psychosis is present or when it is refractory to medications. Developments in its technique (such as the use of ultra-brief pulses) are already being widely used.

TMS has a place in clinical practice, for less severe and less refractory cases. VNS seems to have a long-term benefit for some patients.

Major developments have been seen across the categories of seizure therapies, noninvasive brain stimulation, and surgical approaches. The risks of seizure therapy have been lessened through refinements in treatment technique and the advent of magnetic induction. At the same time, new approaches to dosing and targeting hold out promise for enhancing the efficacy of the noninvasive approach of TMS. The surgical approaches are quickly evolving, informed by new anatomical targets, novel clues to neurophysiological mechanisms, and innovative tools to refine selectivity of targeting. Adding to this, on the horizon stand an array of approaches yet to be systematically evaluated in mood disorders, each offering the hope of deeper, more focal, more selective, and ever less invasive strategies to combat these debilitating illnesses.

\section{DISCLOSURE}

Dr Rosa has no disclosure. Dr Lisanby has received equipment support from Magstim and MagVenture. She has received research grant support from NIH, NARSAD, Stanley, Brainsway, Neuronetics (past), ANS/St Jude Medical (past), Cyberonics (past), DARPA (past).

\section{REFERENCES}

Aouizerate B, Cuny E, Martin-Guehl C, Guehl D, Amieva H, Benazzouz A et al (2004). Deep brain stimulation of the ventral caudate nucleus in the treatment of obsessive-compulsive disorder and major depression. Case report. J Neurosurg 101: 682-686.

Arfai E, Theano G, Montagu JD, Robin AA (1970). A controlled study of polarization in depression. Br J Psychiatry 116: 433-434. Controlled early trial showing no beneficial effects of tDCS.

Bajbouj M, Lisanby SH, Lang UE, Danker-Hopfe H, Heuser I, Neu P (2006). Evidence for impaired cortical inhibition in patients with unipolar major depression. Biol Psychiatry 59: 395-400.

Bajbouj M, Merkl A, Schlaepfer TE, Frick C, Zobel A, Maier W et al (2010). Two-year outcome of vagus nerve stimulation in treatment-resistant depression. J Clin Psychopharmacol 30: 273-281.

Baker AP (1970). Brain stem polarization in the treatment of depression. S Afr Med J 44: 473-475.

Bares M, Kopecek M, Novak T, Stopkova P, Sos P, Kozeny J et al (2009). Low frequency $(1-\mathrm{Hz})$, right prefrontal repetitive transcranial magnetic stimulation (rTMS) compared with venlafaxine ER in the treatment of resistant depression: a double-blind, single-centre, randomized study. J Affect Disord 118: 94-100.

Benabid AL, Pollak P, Gervason C, Hoffmann D, Gao DM, Hommel M et al (1991). Long-term suppression of tremor by chronic stimulation of the ventral intermediate thalamic nucleus. Lancet 337: 403-406.

Ben-Menachem E, Hamberger A, Hedner T, Hammond EJ, Uthman BM, Slater J et al (1995). Effects of vagus nerve stimulation on amino acids and other metabolites in the CSF of patients with partial seizures. Epilepsy Res 20: 221-227.

Berney A, Vingerhoets F, Perrin A, Guex P, Villemure JG, Burkhard PR et al (2002). Effect on mood of subthalamic DBS for Parkinson's disease: a consecutive series of 24 patients. Neurology 59: 1427-1429.

Bewernick BH, Hurlemann R, Matusch A, Kayser S, Grubert C, Hadrysiewicz B et al (2010). Nucleus accumbens deep brain stimulation decreases ratings of 
depression and anxiety in treatment-resistant depression. Biol Psychiatry 67: 110-116.

Bezerra ML, Martinez JV, Nasser JA (1999). Transient acute depression induced by high-frequency deep-brain stimulation. N Engl J Med 341: 1003; author reply 1004.

Bikson M, Bulow P, Stiller JW, Datta A, Battaglia F, Karnup SV et al (2008). Transcranial direct current stimulation for major depression: a general system for quantifying transcranial electrotherapy dosage. Curr Treat Options Neurol 10: 377-385.

Binder DK, Rau G, Starr PA (2003). Hemorrhagic complications of microelectrodeguided deep brain stimulation. Stereotact Funct Neurosurg 80: 28-31.

Bindman LJ, Lippold OC, Redfearn JW (1964). The action of brief polarizing currents on the cerebral cortex of the rat (1) during current flow and (2) in the production of long-lasting after-effects. J Physiol 172: 369-382.

Blomstedt P, Sjoberg RL, Hansson M, Bodlund O, Hariz Ml (2011). Deep brain stimulation in the treatment of depression. Acta Psychiatr Scand 123: 4-11.

Boggio PS, Rigonatti SP, Ribeiro RB, Myczkowski ML, Nitsche MA, Pascual-Leone A et al (2008). A randomized, double-blind clinical trial on the efficacy of cortical direct current stimulation for the treatment of major depression. Int J Neuropsychopharmacol 11: 249-254.

Boutros NN, Krupitsky EM (1998). Cranial electrostimulation therapy. Biol Psychiatry 43: 468-469.

Brunoni AR, Ferrucci R, Bortolomasi M, Vergari M, Tadini L, Boggio PS et al (2011). Transcranial direct current stimulation (tDCS) in unipolar vs. bipolar depressive disorder. Prog Neuropsychopharmacol Biol Psychiatry 35: 96-101.

Butson CR, Mclntyre CC (2006). Role of electrode design on the volume of tissue activated during deep brain stimulation. J Neural Eng 3: 1-8.

Bystritsky A, Kerwin L, Feusner J (2008). A pilot study of cranial electrotherapy stimulation for generalized anxiety disorder. J Clin Psychiatry 69: 412-417.

Carlezon Jr WA, Rohan ML, Mague SD, Meloni EG, Parsegian A, Cayetano K et al (2005). Antidepressant-like effects of cranial stimulation within a low-energy magnetic field in rats. Biol Psychiatry 57: 571-576.

Chanpattana W, Kramer BA, Kunigiri G, Gangadhar BN, Kitphati R, Andrade C (2010). A survey of the practice of electroconvulsive therapy in Asia. J ECT 26: 5-10.

Chistyakov AV, Rubicsek O, Kaplan B, Zaaroor M, Klein E (2010). Safety, tolerability and preliminary evidence for antidepressant efficacy of theta-burst transcranial magnetic stimulation in patients with major depression. Int $J$ Neuropsychopharmacol 13: 387-393.

Conca A, Di Pauli J, Beraus W, Hausmann A, Peschina W, Schneider H et al (2002). Combining high and low frequencies in rTMS antidepressive treatment: preliminary results. Hum Psychopharmacol 17: 353-356.

Cosgrove GR, Rauch SL (2003). Stereotactic cingulotomy. Neurosurg Clin N Am 14: 225-235

Covington III HE, Lobo MK, Maze I, Vialou V, Hyman JM, Zaman S et al (2010). Antidepressant effect of optogenetic stimulation of the medial prefrontal cortex. J Neurosci 30: 16082-16090.

Crawley JN (1985). Neurochemical investigation of the afferent pathway from the vagus nerve to the nucleus tractus solitarius in mediating the 'satiety syndrome' induced by systemic cholecystokinin. Peptides 6(Suppl 1): 133-137.

Creutzfeldt OD, Fromm GH, Kapp H (1962). Influence of transcortical d-c currents on cortical neuronal activity. Exp Neurol 5: 436-452.

Deans JK, Powell AD, Jefferys JG (2007). Sensitivity of coherent oscillations in rat hippocampus to AC electric fields. J Physiol 583: 555-565

Deng ZD, Lisanby SH, Peterchev AV (2011). Electric field strength and focality in electroconvulsive therapy and magnetic seizure therapy: a finite element simulation study. J Neural Eng 8: 016007 . This work showed for the first time a modelling of the electric and magnetic field induced by these seizure therapies.

Dorval AD, Panjwani N, Qi RY, Grill WM (2009). Deep brain stimulation that abolishes Parkinsonian activity in basal ganglia improves thalamic relay fidelity in a computational circuit. Conf Proc IEEE Eng Med Biol Soc 2009: 4230-4233.

Dougherty DD, Thase ME, Howland RH, Evans KC, Harsch H, Kondziolka D (2008). Feasibility study of an implantable cortical stimulation system for patients with major depressive disorder. In: Society of Biological Psychiatry 63rd Annual Meeting, Washington, DC.

Dougherty DD, Weiss AP, Cosgrove GR, Alpert NM, Cassem EH, Nierenberg AA et al (2003). Cerebral metabolic correlates as potential predictors of response to anterior cingulotomy for treatment of major depression. J Neurosurg 99: 1010-1017.

Dunner DL, Rush AJ, Russell JM, Burke M, Woodard S, Wingard P et al (2006). Prospective, long-term, multicenter study of the naturalistic outcomes of patients with treatment-resistant depression. J Clin Psychiatry 67: 688-695.

Dwork AJ, Arango V, Underwood M, llievski B, Rosoklija G, Sackeim HA et al (2004). Absence of histological lesions in primate models of ECT and magnetic seizure therapy. Am J Psychiatry 161: 576-578.
Dwork AJ, Christensen JR, Larsen KB, Scalia J, Underwood MD, Arango V et al (2009). Unaltered neuronal and glial counts in animal models of magnetic seizure therapy and electroconvulsive therapy. Neuroscience 164: 1557-1564.

Elger G, Hoppe C, Falkai P, Rush AJ, Elger CE (2000). Vagus nerve stimulation is associated with mood improvements in epilepsy patients. Epilepsy Res 42: 203-210

Eusebio A, Thevathasan W, Doyle Gaynor L, Pogosyan A, Bye E, Foltynie T et al (2011). Deep brain stimulation can suppress pathological synchronisation in parkinsonian patients. J Neurol Neurosurg Psychiatry 82: 569-573.

Ferdjallah M, Bostick Jr FX, Barr RE (1996). Potential and current density distributions of cranial electrotherapy stimulation (CES) in a four-concentricspheres model. IEEE Trans Biomed Eng 43: 939-943.

Fitzgerald PB, Benitez J, de Castella A, Daskalakis ZJ, Brown TL, Kulkarni J (2006). A randomized, controlled trial of sequential bilateral repetitive transcranial magnetic stimulation for treatment-resistant depression. Am J Psychiatry 163: 88-94.

Fitzgerald PB, Hoy K, Daskalakis ZJ, Kulkarni J (2009a). A randomized trial of the anti-depressant effects of low- and high-frequency transcranial magnetic stimulation in treatment-resistant depression. Depress Anxiety 26: 229-234.

Fitzgerald PB, McQueen S, Herring S, Hoy K, Segrave R, Kulkarni J et al (2009b). A study of the effectiveness of high-frequency left prefrontal cortex transcranial magnetic stimulation in major depression in patients who have not responded to right-sided stimulation. Psychiatry Res 169: 12-15.

Fregni F, Boggio PS, Nitsche MA, Marcolin MA, Rigonatti SP, Pascual-Leone A (2006). Treatment of major depression with transcranial direct current stimulation. Bipolar Disord 8: 203-204. Controlled trial of tDCS with positive results.

Frisina PG, Haroutunian V, Libow LS (2009). The neuropathological basis for depression in Parkinson's disease. Parkinsonism Relat Disord 15: 144-148.

Gangadhar BN, Thirthalli J (2010). Frequency of electroconvulsive therapy sessions in a course. J ECT 26: 181-185.

George MS, Aston-Jones G (2010). Noninvasive techniques for probing neurocircuitry and treating illness: vagus nerve stimulation (VNS), transcranial magnetic stimulation (TMS) and transcranial direct current stimulation (tDCS). Neuropsychopharmacology 35: 301-316.

George MS, Rush AJ, Marangell LB, Sackeim HA, Brannan SK, Davis SM et al (2005). A one-year comparison of vagus nerve stimulation with treatment as usual for treatment-resistant depression. Biol Psychiatry 58: 364-373. This work led to the approval of VNS by the FDA for the treatment of refractory depression.

Goodwin FK, Jamison KR (2007). Manic-Depressive IIIness. Bipolar Disorders and Recurrent Depression 2nd edn. Oxford University Press: New York.

Hadley D, Anderson BS, Borckardt JJ, Arana A, Li X, Nahas Z et al (2011). Safety, tolerability, and effectiveness of high doses of adjunctive daily left prefrontal repetitive transcranial magnetic stimulation for treatment-resistant depression in a clinical setting. J ECT 27: 18-25.

Hamani C, Nobrega JN, Lozano AM (2010). Deep brain stimulation in clinical practice and in animal models. Clin Pharmacol Ther 88: 559-562.

Hansen PE, Ravnkilde B, Videbech P, Clemmensen K, Sturlason R, Reiner M et al (2011). Low-frequency repetitive transcranial magnetic stimulation inferior to electroconvulsive therapy in treating depression. J ECT 27: 26-32.

Harden CL, Pulver MC, Ravdin LD, Nikolov B, Halper JP, Labar DR (2000). A pilot study of mood in epilepsy patients treated with vagus nerve stimulation. Epilepsy Behav 1: 93-99.

Harel EV, Zangen A, Roth Y, Reti I, Braw Y, Levkovitz Y (2011). H-coil repetitive transcranial magnetic stimulation for the treatment of bipolar depression: an add-on, safety and feasibility study. World J Biol Psychiatry 12: 119-126.

Hauptman JS, DeSalles AA, Espinoza R, Sedrak M, Ishida W (2008). Potential surgical targets for deep brain stimulation in treatment-resistant depression. Neurosurg Focus 25: E3.

Heath RG (1963). Electrical self-stimulation of the brain in man. Am J Psychiatry 120: $571-577$

Henry TR, Bakay RA, Votaw JR, Pennell PB, Epstein CM, Faber TL et al (1998). Brain blood flow alterations induced by therapeutic vagus nerve stimulation in partial epilepsy: I. Acute effects at high and low levels of stimulation. Epilepsia 39: 983-990.

Herrington JD, Heller W, Mohanty A, Engels AS, Banich MT, Webb AG et al (2010). Localization of asymmetric brain function in emotion and depression. Psychophysiology 47: 442-454.

Holtzheimer III PE, McDonald WM, Mufti M, Kelley ME, Quinn S, Corso G et al (2010). Accelerated repetitive transcranial magnetic stimulation for treatmentresistant depression. Depress Anxiety 27: 960-963.

Hoy KE, Fitzgerald PB (2010). Introducing magnetic seizure therapy: a novel therapy for treatment resistant depression. Aust NZ J Psychiatry 44: 591-598. 
Husain MM, Rush AJ, Fink M, Knapp R, Petrides G, Rummans T et al (2004). Speed of response and remission in major depressive disorder with acute electroconvulsive therapy (ECT): a Consortium for Research in ECT (CORE) report. J Clin Psychiatry 65: 485-491.

Jarzembski WB (1985). Electrical stimulation and substance abuse treatment. Neurobehav Toxicol Teratol 7: 119-123.

Jimenez F, Velasco F, Salin-Pascual R, Hernandez JA, Velasco M, Criales JL et al (2005). A patient with a resistant major depression disorder treated with deep brain stimulation in the inferior thalamic peduncle. Neurosurgery 57: 585-593; discussion 585-593.

Juckel G, Uhl I, Padberg F, Brune M, Winter C (2009). Psychosurgery and deep brain stimulation as ultima ratio treatment for refractory depression. Eur Arch Psychiatry Clin Neurosci 259: 1-7.

Katz EJ, Ilev IK, Krauthamer V, Kim do H, Weinreich D (2010). Excitation of primary afferent neurons by near-infrared light in vitro. Neuroreport 21: 662-666.

Kayser S, Bewernick B, Axmacher N, Schlaepfer TE (2009). Magnetic seizure therapy of treatment-resistant depression in a patient with bipolar disorder. J ECT 25: 137-140.

Kayser S, Bewernick BH, Grubert C, Hadrysiewicz BL, Axmacher N, Schlaepfer TE (2010). Antidepressant effects, of magnetic seizure therapy and electroconvulsive therapy, in treatment-resistant depression. J Psychiatr Res 45: 569-576.

Kellner CH, Knapp R, Husain MM, Rasmussen K, Sampson S, Cullum M et al (2010). Bifrontal, bitemporal and right unilateral electrode placement in ECT: randomised trial. $\mathrm{Br} J$ Psychiatry 196: 226-234. Controlled multi-site comparison of efficacy and cognitive side effects of the main electrode placements used in ECT practice.

Kellner CH, Knapp RG, Petrides G, Rummans TA, Husain MM, Rasmussen K et al (2006). Continuation electroconvulsive therapy vs pharmacotherapy for relapse prevention in major depression: a multisite study from the Consortium for Research in Electroconvulsive Therapy (CORE). Arch Gen Psychiatry 63 1337-1344.

Kennedy SH, Giacobbe P, Rizvi SJ, Placenza FM, Nishikawa Y, Mayberg HS et al (2011). Deep brain stimulation for treatment-resistant depression: follow-up after 3 to 6 years. Am J Psychiatry 168: 502-510.

Kirov R, Weiss C, Siebner HR, Born J, Marshall L (2009). Slow oscillation electrical brain stimulation during waking promotes EEG theta activity and memory encoding. Proc Natl Acad Sci USA 106: 15460-15465.

Kirsch DL, Smith RB (2000). The use of cranial electrotherapy stimulation in the management of chronic pain: A review. Neuro Rehabilitation 14: 85-94.

Klawansky S, Yeung A, Berkey C, Shah N, Phan H, Chalmers TC (1995). Meta-analysis of randomized controlled trials of cranial electrostimulation. Efficacy in treating selected psychological and physiological conditions. J Nerv Ment Dis 183: 478-484.

Krupitsky EM, Burakov AM, Karandashova GF, Katsnelson Ja S, Lebedev VP, Grinenko A et al (1991). The administration of transcranial electric treatment for affective disturbances therapy in alcoholic patients. Drug Alcohol Depend 27: $1-6$.

Lee WH, Deng ZD, Kim TS, Laine AF, Lisanby SH, Peterchev AV (2010). Regional electric field induced by electroconvulsive therapy: a finite element simulation study. Conf Proc IEEE Eng Med Biol Soc 2010: 2045-2048.

Leiphart JW, Valone III FH (2010). Stereotactic lesions for the treatment of psychiatric disorders. J Neurosurg 113: 1204-1211.

Levkovitz Y, Harel EV, Roth Y, Braw Y, Most D, Katz LN et al (2009). Deep transcranial magnetic stimulation over the prefrontal cortex: evaluation of antidepressant and cognitive effects in depressive patients. Brain Stimul 2: 188-200.

Li X, Ricci R, Large CH, Anderson B, Nahas Z, Bohning DE et al (2010). Interleaved transcranial magnetic stimulation and $\mathrm{fMRl}$ suggests that lamotrigine and valproic acid have different effects on corticolimbic activity. Psychopharmacology (Berl) 209: 233-244.

Liebetanz D, Nitsche MA, Tergau F, Paulus W (2002). Pharmacological approach to the mechanisms of transcranial DC-stimulation-induced after-effects of human motor cortex excitability. Brain 125: 2238-2247.

Lisanby SH, Husain MM, Rosenquist PB, Maixner D, Gutierrez R, Krystal A et al (2009). Daily left prefrontal repetitive transcranial magnetic stimulation in the acute treatment of major depression: clinical predictors of outcome in a multisite, randomized controlled clinical trial. Neuropsychopharmacology 34: 522-534.

Lisanby SH, Luber B, Schlaepfer TE, Sackeim HA (2003a). Safety and feasibility of magnetic seizure therapy (MST) in major depression: randomized within-subject comparison with electroconvulsive therapy. Neuropsychopharmacology 28: 1852-1865.

Lisanby SH, Moscrip T, Morales O, Luber B, Schroeder C, Sackeim HA (2003b). Neurophysiological characterization of magnetic seizure therapy (MST) in non-human primates. Supp/ Clin Neurophysio/ 56: 81-99. This paper describes the origins of magnetic seizure therapy and its first use in humans.

Lisanby SH, Schlaepfer TE, Fisch HU, Sackeim HA (2001). Magnetic seizure therapy of major depression. Arch Gen Psychiatry 58: 303-305.

Loo CK, Kaill A, Paton P, Simpson B (2010a). The difficult-to-treat electroconvulsive therapy patient - strategies for augmenting outcomes. J Affect Disord 124: 219-227

Loo CK, Mitchell PB, Croker VM, Malhi GS, Wen W, Gandevia SC et al (2003). Double-blind controlled investigation of bilateral prefrontal transcranial magnetic stimulation for the treatment of resistant major depression. Psychol Med 33 : 33-40.

Loo CK, Sachdev P, Martin D, Pigot M, Alonzo A, Malhi GS et al (2010b). A doubleblind, sham-controlled trial of transcranial direct current stimulation for the treatment of depression. Int J Neuropsychopharmacol 13: 61-69.

Lozano AM, Mayberg HS, Giacobbe P, Hamani C, Craddock RC, Kennedy SH (2008). Subcallosal cingulate gyrus deep brain stimulation for treatment-resistant depression. Biol Psychiatry 64: 461-467.

Malone Jr DA, Dougherty DD, Rezai AR, Carpenter LL, Friehs GM, Eskandar EN et al (2009). Deep brain stimulation of the ventral capsule/ventral striatum for treatment-resistant depression. Biol Psychiatry 65: 267-275.

Marangell LB, Suppes T, Zboyan HA, Prashad SJ, Fischer G, Snow D et al (2008). A 1-year pilot study of vagus nerve stimulation in treatment-resistant rapidcycling bipolar disorder. J Clin Psychiatry 69: 183-189.

Marshall L, Helgadottir H, Molle M, Born J (2006). Boosting slow oscillations during sleep potentiates memory. Nature 444: 610-613.

Mathew M, Amat-Roldan I, Andres R, Santos SI, Artigas D, Soriano E et al (2010). Signalling effect of NIR pulsed lasers on axonal growth. J Neurosci Methods 186 196-201.

Mayberg HS, Brannan SK, Tekell JL, Silva JA, Mahurin RK, McGinnis S et al (2000). Regional metabolic effects of fluoxetine in major depression: serial changes and relationship to clinical response. Biol Psychiatry 48: 830-843.

Mayberg HS, Liotti M, Brannan SK, McGinnis S, Mahurin RK, Jerabek PA et al (1999). Reciprocal limbic-cortical function and negative mood: converging PET findings in depression and normal sadness. Am J Psychiatry 156: 675-682.

Mayberg HS, Lozano AM, Voon V, McNeely HE, Seminowicz D, Hamani C et al (2005). Deep brain stimulation for treatment-resistant depression. Neuron 45: $651-660$.

McIntyre CC, Savasta M, Kerkerian-Le Goff L, Vitek JL (2004). Uncovering the mechanism(s) of action of deep brain stimulation: activation, inhibition, or both. Clin Neurophysiol 115: 1239-1248.

Minhas P, Bansal V, Patel J, Ho JS, Diaz J, Datta A et al (2010). Electrodes for high-definition transcutaneous DC stimulation for applications in drug delivery and electrotherapy, including tDCS. J Neurosci Methods 190: 188-197.

Miniussi C, Rossini PM (2011). Transcranial magnetic stimulation in cognitive rehabilitation. Neuropsychol Rehabil 30: 1-23.

Momose-Sato Y, Sato K (2011). The embryonic brain and development of vagal pathways. Respir Physiol Neurobiol 178: 163-173.

Monk CS, Klein RG, Telzer EH, Schroth EA, Mannuzza S, Moulton III JL et al (2008). Amygdala and nucleus accumbens activation to emotional facial expressions in children and adolescents at risk for major depression. Am J Psychiatry 165 90-98.

Mottaghy FM, Keller CE, Gangitano M, Ly J, Thall M, Parker JA et al (2002). Correlation of cerebral blood flow and treatment effects of repetitive transcrania magnetic stimulation in depressed patients. Psychiatry Res 115: 1-14.

Nahas Z, Anderson BS, Borckardt J, Arana AB, George MS, Reeves ST et al (2010). Bilateral epidural prefrontal cortical stimulation for treatment-resistant depression. Biol Psychiatry 67: 101-109.

Nahas Z, Marangell LB, Husain MM, Rush AJ, Sackeim HA, Lisanby SH et al (2005). Two-year outcome of vagus nerve stimulation (VNS) for treatment of major depressive episodes. J Clin Psychiatry 66: 1097-1104.

Nias DK, Shapiro MB (1974). The effects of small electrical currents upon depressive symptoms. Br J Psychiatry 125: 414-415.

Nitsche MA, Fricke K, Henschke U, Schlitterlau A, Liebetanz D, Lang N et al (2003). Pharmacological modulation of cortical excitability shifts induced by transcrania direct current stimulation in humans. J Physiol 553: 293-301.

Nitsche MA, Jaussi W, Liebetanz D, Lang N, Tergau F, Paulus W (2004). Consolidation of human motor cortical neuroplasticity by D-cycloserine. Neuropsychopharmacology 29: 1573-1578.

Nobler MS, Oquendo MA, Kegeles LS, Malone KM, Campbell CC, Sackeim HA et al (2001). Decreased regional brain metabolism after ect. Am J Psychiatry 158: 305-308.

Nowak LG, Bullier J (1998). Axons, but not cell bodies, are activated by electrical stimulation in cortical gray matter. I. Evidence from chronaxie measurements. Exp Brain Res 118: 477-488. 
Nuttin B, Cosyns P, Demeulemeester H, Gybels J, Meyerson B (1999). Electrical stimulation in anterior limbs of internal capsules in patients with obsessivecompulsive disorder. Lancet 354: 1526

O'Reardon JP, Solvason HB, Janicak PG, Sampson S, Isenberg KE, Nahas Z et al (2007). Efficacy and safety of transcranial magnetic stimulation in the acute treatment of major depression: a multisite randomized controlled trial. Biol Psychiatry 62: 1208-1216. Results of this study led to the approval by the FDA of the use of rTMS for the treament of depression.

Osuch EA, Benson BE, Luckenbaugh DA, Geraci M, Post RM, McCann U (2009). Repetitive TMS combined with exposure therapy for PTSD: a preliminary study. J Anxiety Disord 23: 54-59.

Pallanti S, Bernardi S, Di Rollo A, Antonini S, Quercioli L (2010). Unilateral low frequency versus sequential bilateral repetitive transcranial magnetic stimulation: is simpler better for treatment of resistant depression? Neuroscience 167: 323-328.

Palm U, Keeser D, Schiller C, Fintescu Z, Nitsche M, Reisinger E et al (2008). Skin lesions after treatment with transcranial direct current stimulation (tDCS). Brain Stimul 1: 386-387.

Paulus W, Classen J, Cohen LG, Large CH, Di Lazzaro V, Nitsche M et al (2008). State of the art: pharmacologic effects on cortical excitability measures tested by transcranial magnetic stimulation. Brain Stimul 1: 151-163.

Penry JK, Dean JC (1990). Prevention of intractable partial seizures by intermittent vagal stimulation in humans: preliminary results. Epilepsia 31(Suppl 2): S40-S43.

Peterchev AV, Murphy DL, Lisanby SH (2010a). Repetitive transcranial magnetic stimulator with controllable pulse parameters (cTMS). Conf Proc IEEE Eng Med Biol Soc 2010: 2922-2926.

Peterchev AV, Rosa MA, Deng ZD, Prudic J, Lisanby SH (2010b). Electroconvulsive therapy stimulus parameters: rethinking dosage. J ECT 26: 159-174.

Prudic J, Peyser S, Sackeim HA (2000). Subjective memory complaints: a review of patient self-assessment of memory after electroconvulsive therapy. J ECT 16: $121-132$

Purpura DP, McMurtry JG (1965). Intracellular activities and evoked potential changes during polarization of motor cortex. J Neurophysiol 28: 166-185.

Radman T, Datta A, Peterchev AV (2007). In vitro modulation of endogenous rhythms by AC electric fields: Syncing with clinical brain stimulation. J Physiol 584: 369-370.

Ramsay JC, Schlagenhauf G (1966). Treatment of depression with low voltage direct current. South Med J 59: 932-934.

Rohan M, Parow A, Stoll AL, Demopulos C, Friedman S, Dager S et al (2004). Low-field magnetic stimulation in bipolar depression using an MRI-based stimulator. Am Jo Psychiatry 161: 93-98.

Rosa MA, Abdo GL, Lisanby S, Peterchev AV (2010). Seizure induction with lowamplitude-current (0.5A) electroconvulsive therapy. J ECT (in press).

Rosa MA, Rosa MO, Daltio CS, Abreu LN, Marcolin MA (2006). Open trial on the efficacy of right unilateral electroconvulsive therapy with titration and high charge. J ECT 22: 237-239.

Rossi S, Hallett M, Rossini PM, Pascual-Leone A (2009). Safety, ethical considerations, and application guidelines for the use of transcranial magnetic stimulation in clinical practice and research. Clin Neurophysiol 120: 2008-2039.

Rowny SB, Benzl K, Lisanby SH (2009a). Translational development strategy for magnetic seizure therapy. Exp Neurol 219: 27-35.

Rowny SB, Cycowicz YM, McClintock SM, Truesdale MD, Luber B, Lisanby SH (2009b). Differential heart rate response to magnetic seizure therapy (MST) relative to electroconvulsive therapy: a nonhuman primate model. Neuroimage 47: 1086-1091.

Rush AJ, George MS, Sackeim HA, Marangell LB, Husain MM, Giller C et al (2000). Vagus nerve stimulation (VNS) for treatment-resistant depressions: a multicenter study. Biol Psychiatry 47: 276-286.

Rush AJ, Marangell LB, Sackeim HA, George MS, Brannan SK, Davis SM et al (2005a). Vagus nerve stimulation for treatment-resistant depression: a randomized, controlled acute phase trial. Biol Psychiatry 58: 347-354.

Rush AJ, Sackeim HA, Marangell LB, George MS, Brannan SK, Davis SM et al (2005b). Effects of 12 months of vagus nerve stimulation in treatment-resistant depression: a naturalistic study. Biol Psychiatry 58: 355-363.

Rush AJ, Trivedi MH, Wisniewski SR, Nierenberg AA, Stewart JW, Warden D et al (2006). Acute and longer-term outcomes in depressed outpatients requiring one or several treatment steps: a STAR*D report. Am J Psychiatry 163: 1905-1917.

Sackeim H, Decina P, Prohovnik I, Malitz S (1987). Seizure threshold in electroconvulsive therapy. Effects of sex, age, electrode placement, and number of treatments. Arch Gen Psychiatry 44: 355-360.

Sackeim HA (1991). Optimizing unilateral electroconvulsive therapy. Convuls Ther 7 : 201-212

Sackeim HA (1999). The anticonvulsant hypothesis of the mechanisms of action of ECT: current status. J ECT 15: 5-26.
Sackeim HA, Brannan SK, Rush AJ, George MS, Marangell LB, Allen J (2007a). Durability of antidepressant response to vagus nerve stimulation (VNS). Int J Neuropsychopharmacol 10: 817-826.

Sackeim HA, Prudic J, Fuller R, Keilp J, Lavori PW, Olfson M (2007b). The cognitive effects of electroconvulsive therapy in community settings. Neuropsychopharmacology 32: 244-254.

Sackeim HA, Prudic J, Nobler MS, Fitzsimons L, Lisanby SH, Payne N et al (2008). Effects of pulse width and electrode placement on the efficacy and cognitive effects of electroconvulsive therapy. Brain Stimul 1: 71-83. Study that highlighted the importance of different electrical parameters for clinical efficacy and side effects profile.

Sartorius A, Henn FA (2007). Deep brain stimulation of the lateral habenula in treatment resistant major depression. Med Hypotheses 69: 1305-1308.

Sartorius A, Kiening KL, Kirsch P, von Gall CC, Haberkorn U, Unterberg AW et al (2010). Remission of major depression under deep brain stimulation of the lateral habenula in a therapy-refractory patient. Biol Psychiatry 67: e9-e11.

Schlaepfer TE, Cohen MX, Frick C, Kosel M, Brodesser D, Axmacher N et al (2008a). Deep brain stimulation to reward circuitry alleviates anhedonia in refractory major depression. Neuropsychopharmacology 33: 368-377.

Schlaepfer TE, Frick C, Zobel A, Maier W, Heuser I, Bajbouj M et al (2008b). Vagus nerve stimulation for depression: efficacy and safety in a European study. Psychol Med 38: 651-661.

Schlaepfer TE, George MS, Mayberg H (2010). WFSBP guidelines on brain stimulation treatments in psychiatry. World J Biol Psychiatry 11: 2-18.

Scholfield CN (1990). Properties of K-currents in unmyelinated presynaptic axons of brain revealed revealed by extracellular polarisation. Brain Res 507: $121-128$

Schutter DJ (2009). Antidepressant efficacy of high-frequency transcranial magnetic stimulation over the left dorsolateral prefrontal cortex in double-blind shamcontrolled designs: a meta-analysis. Psychol Med 39: 65-75.

Sekirnjak C, Hottowy P, Sher A, Dabrowski W, Litke AM, Chichilnisky EJ (2006). Electrical stimulation of mammalian retinal ganglion cells with multielectrode arrays. J Neurophysiol 95: 3311-3327.

Seminowicz DA, Mayberg HS, McIntosh AR, Goldapple K, Kennedy S, Segal Z et al (2004). Limbic-frontal circuitry in major depression: a path modeling metanalysis. Neuroimage 22: 409-418.

Shorter E, Healy D (2007). Shock Therapy: A History of Electroconvulsive Treatment in Mental Illness. Rutgers University Press: New Brunswick.

Sommer M, Alfaro A, Rummel M, Speck S, Lang N, Tings T et al (2006). Half sine, monophasic and biphasic transcranial magnetic stimulation of the human motor cortex. Clin Neurophysiol 117: 838-844.

Spellman T, Peterchev AV, Lisanby SH (2009). Focal electrically administered seizure therapy: a novel form of ECT illustrates the roles of current directionality, polarity, and electrode configuration in seizure induction. Neuropsychopharmacology 34: 2002-2010. This paper describes FEAST basic mechanisms and technique in non-human primates.

Stagg CJ, Nitsche MA (2011). Physiological basis of transcranial direct current stimulation. Neuroscientist 17: 37-53.

Stern WM, Tormos JM, Press DZ, Pearlman C, Pascual-Leone A (2007). Antidepressant effects of high and low frequency repetitive transcranial magnetic stimulation to the dorsolateral prefrontal cortex: a double-blind, randomized, placebo-controlled trial. J Neuropsychiatry Clin Neurosci 19: 179-186.

Teo JT, Swayne OB, Rothwell JC (2007). Further evidence for NMDA-dependence of the after-effects of human theta burst stimulation. Clin Neurophysiol 118: 1649-1651.

Thomas MJ, Malenka RC, Bonci A (2000). Modulation of long-term depression by dopamine in the mesolimbic system. J Neurosci 20: 5581-5586.

Tyler WJ, Tufail Y, Finsterwald M, Tauchmann ML, Olson EJ, Majestic C (2008). Remote excitation of neuronal circuits using low-intensity, low-frequency ultrasound. PLoS One 3: e3511.

Vago DR, Epstein J, Catenaccio E, Stern E (2011). Identification of neural targets for the treatment of psychiatric disorders: the role of functional neuroimaging. Neurosurg Clin N Am 22: 279-305.

Vedeniapin A, Cheng L, George MS (2010). Feasibility of simultaneous cognitive behavioral therapy and left prefrontal rTMS for treatment resistant depression. Brain Stimul 3: 207-210

Velasco F, Velasco M, Jimenez F, Velasco AL, Salin-Pascual R (2005). Neurobiological background for performing surgical intervention in the inferior thalamic peduncle for treatment of major depression disorders. Neurosurgery 57: 439-448.

Volkow ND, Tomasi D, Wang GJ, Fowler JS, Telang F, Wang R et al (2010). Effects of low-field magnetic stimulation on brain glucose metabolism. Neuroimage 51 : $623-628$ 
Wagner T, Valero-Cabre A, Pascual-Leone A (2007). Noninvasive human brain stimulation. Annu Rev Biomed Eng 9: 527-565.

Weiner RD, Coffey CE, Fochtmann LJ, Greenberg RM, Isenberg KE, Kellner CH et al (2001). The Practice of Electroconvulsive Therapy: Recommendations for Treatment, Training and Privileging, 2nd edn (Completely Revised). American Psychiatric Association: Washington, DC.

White PF, Amos Q, Zhang Y, Stool L, Husain MM, Thornton L et al (2006). Anesthetic considerations for magnetic seizure therapy: a novel therapy for severe depression. Anesth Analg 103: 76-80, table of contents.
Yang LM, Hu B, Xia YH, Zhang BL, Zhao H (2008). Lateral habenula lesions improve the behavioral response in depressed rats via increasing the serotonin level in dorsal raphe nucleus. Behav Brain Res 188 84-90.

Zhang F, Aravanis AM, Adamantidis A, de Lecea L, Deisseroth K (2007). Circuitbreakers: optical technologies for probing neural signals and systems. Nat Rev Neurosci 8: 577-581.

Zuo Y, Smith DC, Jensen RA (2007). Vagus nerve stimulation potentiates hippocampal LTP in freely-moving rats. Physiol Behav 90: 583-589. 